\title{
O tema sexualidade humana nos livros didáticos de Biologia mais distribuídos pelo Programa Nacional do Livro Didático 2015
}

\author{
Human sexuality in the most distributed biology textbooks by the National \\ Program of Textbooks 2015 in Brazil
}

\author{
El tema sexualidad humana en los libros didácticos de Biología más \\ distribuidos por el Programa Nacional del Libro Didáctico 2015
}

\begin{abstract}
Bruno Ferreira ${ }^{2}$
Luisa Aguiar Machado ${ }^{3}$

Ana Júlia Lemos Alves Pedreira ${ }^{4}$

Resumo: A restrição da abordagem do tema sexualidade nas escolas e no livro didático pode ser problemática, visto que ao não se debater sobre conteúdos relativos à sexualidade humana, dúvidas importantes sobre a saúde no que diz respeito ao âmbito sexual, podem não ser esclarecidas. Ao não se debater sobre as questões sociais da sexualidade humana, preconceitos e discriminações, contra homossexuais, podem ser gerados. O objetivo desse estudo foi investigar como as duas coleções de livros didáticos de Biologia, mais distribuídas no Brasil, no ano de 2015, pelo PNLD, abordam o tema, além de verificar nas coleções dos mesmos autores no ano de 2018. Foi utilizada a análise de conteúdo para analisar as quatro coleções. Foi verificado que a linguagem presente nos textos dos livros didáticos ainda apresenta um padrão heteronormativo, não abordando a diversidade da sexualidade humana, focando principalmente na sexualidade como sinônimo e forma de reprodução. Assim, a discussão dos temas de sexualidade dentro da sala de aula deveria abranger mais tópicos dentro do conteúdo, a fim de aprofundar a discussão e poder então cumprir o critério de construção de uma sociedade democrática. Espera-se que esse estudo contribua para a desmistificação dos tabus que envolvem a sexualidade humana; bem como que auxilie na elaboração de livros didáticos com um olhar mais social do tema sexualidade, com o intuito de desconstruir preconceitos de gênero e orientação sexual.
\end{abstract}

Palavras-chave: Sexualidade. Educação sexual. Livro didático. Ensino de Biologia.

Abstract: Restricting the approach to sexuality in school's textbooks can be problematic, as failure to discuss human sexuality content leads to important questions and decisions about sexual health. Without discussion, these uncertainties may not be clarified. The lack of debate on the social issues of human sexuality can generate prejudice and discrimination against homosexuals. Thus, this study aimed to investigate how the two sets of biology textbooks distributed in Brazil by PNLD (National Program for Textbooks - PNLD), approach the theme. The specimens from 2015 and 2018 were investigated through content analysis to evaluate the four sets. We verified that the language present in the texts of the textbooks still presents a heteronormative pattern, not addressing the diversity of human sexuality. The focus is mainly on sexuality as a synonym for the form of reproduction. The discussion of sexuality issues within the classroom should encompass a more significant number of topics within the content, so that discussion may be deepened and then meet the criteria of building a democratic society. It is hoped that this study will contribute to the demystification of taboos involving human sexuality and that it will help in the preparation of textbooks with a more social perspective on sexuality in order to deconstruct gender biases and sexual orientation.

Keywords: Sexuality. Sexual education. Textbook. Biology teaching.

\footnotetext{
${ }^{1}$ Submetido em: 25 jul. 2019 - Aceito em: 03 set. 2020 - Publicado em: 20 nov. 2020

${ }^{2}$ Universidade de Brasília (UnB) - E-mail: bnferreira96@yahoo.com.br

${ }^{3}$ Universidade de Brasília (UnB) - E-mail: luisa.dsam@gmail.com

${ }^{4}$ Universidade de Brasília (UnB) - E-mail: anajuliapedreira@unb.br
} 
Resumen: Restringir el enfoque de la sexualidad en las escuelas y los libros de texto puede ser problemático, ya que la falta de discusión sobre el contenido de la sexualidad humana lleva a importantes preguntas y decisiones sobre la salud sexual. Sin discusión, estas incertidumbres pueden no aclararse. La falta de debate sobre los problemas sociales de la sexualidad humana puede generar prejuicios y discriminación contra los homosexuales. Por lo tanto, el objetivo de este estudio fue investigar cómo las dos colecciones de libros de texto de biología distribuidos en Brasil por Programa Nacional para Livros Textos (PNLD), abordan el tema. Las muestras de 2015 y 2018 se investigaron a través del análisis de contenido para evaluar las cuatro colecciones. Verificamos que el lenguaje presente en los textos de los libros de texto todavía presenta un patrón heteronormativo, no aborda la diversidad de la sexualidad humana. La atención se centra principalmente en la sexualidad como sinónimo de forma de reproducción. La discusión sobre temas de sexualidad dentro del aula debe abarcar una mayor cantidad de temas dentro del contenido, de modo que la discusión pueda profundizarse y luego cumplir con los criterios para construir una sociedad democrática. Se espera que este estudio contribuya a la desmitificación de los tabúes relacionados con la sexualidad humana, y que ayude en la preparación de libros de texto con una perspectiva más social sobre la sexualidad, para deconstruir los prejuicios de género y la orientación sexual.

Palabras clave: Sexualidad. Educación sexual. Libro de texto. Enseñanza de Biología.

\section{Introdução}

De acordo com Maia (2010, p. 2), "Sexualidade é o nome que damos para o aspecto da vida humana que inclui as sensações corpóreas e subjetivas que envolvem, também, as questões emocionais", ou seja, sexualidade não está restrita à manifestação da atividade sexual, mas também encontra-se relacionada às questões subjetivas e emocionais de cada indivíduo. Em sentido amplo, a sexualidade permeia, além da prática sexual, questões de gênero, orientação sexual, reprodução, prazer e afeto (MAIA, 2010). A sexualidade sempre gerou polêmicas por mexer com a fantasia das pessoas, mesmo após a revolução sexual promovida pela globalização e pelos meios de comunicação, questões ligadas ao sexo e sexualidade continuam sendo um tabu (BERALDO, 2003).

No ambiente escolar, a sexualidade é parte da vida de adolescentes, que começam a socialização e desenvolvimento corporal devido aos hormônios que se manifestam mais intensamente nessa etapa da vida. Em virtude disso, refletir sobre a sexualidade humana traz um certo "puritanismo", que engessa a discussão sobre o tema e não permite que preconceitos e estereótipos sejam desmistificados (SILVA, 2013).

Pensando nos tabus que permeiam a sexualidade, é fundamental que a escola seja o intermédio no sentido de quebrar os paradigmas sobre a sexualidade humana. Silva (2013, p. 19) afirma:

[...] é preciso que a Escola, através da representação do Estado, protagonize a questão e suas variantes para que inúmeros conceitos e pré-conceitos sejam esclarecidos, como, por exemplo: dúvidas sobre prevenção de IST's, tabus sobre homossexualidade, gravidez na adolescência, amor, paixão, o conhecimento do próprio corpo e do corpo do Outro [...].

Ao ser abordado na escola pelas disciplinas de Ciências e Biologia, o tema sexualidade é restrito, na maioria das vezes, aos conteúdos específicos da Biologia, como reprodução, mudanças hormonais e fisiológicas, infecções sexualmente transmissíveis (ISTs), ou seja, conteúdos que dizem respeito à Biologia do ser humano. Apesar dessa condição, o 
entendimento biológico é insuficiente para a amplitude do tema e compreensão do indivíduo, sendo fundamental a leitura de outros aspectos, tais como emocionais, socioculturais e históricos, para trabalhar o tema educação e sexualidade (RIBEIRO; RENNES, 1990). Afinal, a vivência da sexualidade ultrapassa as relações sexuais e reprodução, trazendo consigo afeto, amizade, amor, intimidade e respeito ao corpo e à vida (SOUZA; COAN, 2013).

\section{Sexualidade e sociedade}

Para a realização desse estudo, consideramos a vivência da sexualidade humana como: "O exercício da sexualidade humana, entendido como parte do desenvolvimento humano, envolve conceitos como afetividade, prazer, troca, autonomia de decisão e respeito, constituindo-se, assim, em um direito fundamental” (DINIZ; PEREIRA, 2009, p. 227).

Além disso, também tomamos a colocação de Louro (2000, p. 9), como norteadora desse estudo, ao afirmar que "[...] podemos entender que a sexualidade envolve rituais, linguagens, fantasias, representações, símbolos, convenções... Processos profundamente culturais e plurais".

Cano, Ferriani e Gomes (2000) traçam um breve histórico da construção dos tabus que envolvem a sexualidade humana. Afirmam que à medida que a sociedade se organizou na estrutura familiar "tradicional" (mãe, pai e filhos) dentro de um sistema patriarcal e a concepção religiosa cristã passou a vigorar com mais força, o sexo passou a ser visto apenas para procriação. Desta forma, mitos e tabus relacionados à masturbação e à homossexualidade, por exemplo, foram construídos, e essas vertentes da sexualidade humana passaram a ser encaradas como pecado, promiscuidade e motivo de vergonha (CANO; FERRIANI; GOMES, 2000).

Macedo et al. (2013, p. 106) mostram que os tabus vinculados à sexualidade podem ter origem no próprio ambiente familiar, sendo fomentados pelos pais: “[...] o fator vergonha é o grande inibidor do diálogo com a família, inferindo-nos a pensar sobre o relacionamento entre pais e filhos e as restrições existentes sobre alguns assuntos, como, por exemplo, a própria sexualidade".

Para Cano, Ferriani e Gomes (2000, p. 21): “A sexualidade dos filhos traz à tona para muitos pais aspectos reprimidos da própria sexualidade". Ao falar de sexualidade e gênero, também se destaca a importância da dissociação desses dois conceitos, que usualmente são tratados como complementares ou são lidos como intrinsecamente ligados, apesar da compreensão da distinção entre os dois tópicos.

A inconsonância entre gênero e sexualidade é assentida a partir de duas perspectivas divergentes: a sexualidade desapegada do gênero, quebrando os argumentos reducionistas que os vincula e a outra que mostra possibilidades de gênero que não estejam prédeterminadas por formas de heterossexualidade predominante (BUTLER, 2016). Assim, entende-se que gênero e sexualidade são temas independentes intrinsecamente e devem ser tratados com essa distinção. Esse tratamento visa diminuir os preconceitos e melhorar o 
entendimento das diversas vertentes tanto da sexualidade quanto do conceito de gênero. É, também, necessário perceber como suas regulações podem gerar esses preconceitos e tabus dentro da sociedade. Esses, que permeiam a discussão da sexualidade humana, impedem que dúvidas importantes sobre o respeito à diversidade e sobre a saúde humana, sejam esclarecidas. Desde questões que abordam a vivência da prática sexual saudável, até questões ligadas à desconstrução de preconceitos e o respeito à diversidade sexual e de gênero.

Nesse sentido, a escola deve vir para reparar e sanar os tabus construídos socialmente e que são reverberados no ambiente familiar. A presença de temas que tratem sobre gênero e sexualidade nos livros didáticos, pode abrir espaço para a abordagem desses, ampliando essa discussão dentro do ambiente escolar, auxiliando, assim, na desconstrução desses tabus.

\section{Sexualidade na Escola}

Para Macedo et al. (2013) é importante que a abordagem da sexualidade ocorra no universo escolar, uma vez que essa revela uma trajetória social, indo além do espaço do indivíduo. Já Imperatori et al. (2008) afirmam que a sexualidade se expressa de várias formas nas escolas, cabendo à instituição escolar ampliar o conhecimento sobre a sexualidade.

Apesar dos conceitos apresentados neste estudo, para definir a sexualidade é importante sempre levar em consideração as questões socioculturais e subjetivas que permeiam o tema. $\mathrm{O}$ conhecimento passado no ambiente escolar parece restringir-se às questões majoritariamente biológicas da temática, como afirmam Imperatori et al. (2008, p. 2): “[...] vale ressaltar que não é evidente que a diversidade de orientação sexual e de gênero sejam trabalhadas na formação escolar, que parece estabelecer uma continuidade entre a reflexão da sexualidade e da reprodução".

Teixeira, Araújo e Souza (2017) também reforçam o que foi dito por Imperatori et al. (2008), afirmando que trabalhos realizados para o ensino de Educação Sexual na Educação Básica, são influenciados pela "concepção biologicista", ou seja, uma visão técnica e determinista de assuntos específicos das Ciências Biológicas. Isso ocorre apesar da consciência de que existem aspectos voltados para as Ciências Humanas e Sociais, ao tratar da sexualidade humana.

A escola possui um papel essencial no desenvolvimento do adolescente por tratar de temas complexos, como mostra Beraldo (2003) ao apontar que a escola é um ambiente de interação com o mundo. A autora afirma ainda que, além do ambiente familiar, é na escola que temas complexos são trabalhados, levando em consideração a formação afetiva e emocional dos estudantes.

Sendo assim, é importante desconstruir a visão de que a Biologia, por si só, basta para explicar questões subjetivas da sexualidade humana, sendo necessária a incorporação da visão social para trabalhar os conteúdos da sexualidade humana.

O livro didático é uma ferramenta utilizada por professores dentro e fora da sala de aula, se estendendo para o uso no preparo das aulas, como guia de conteúdo, como 
planejamento do ano letivo e também para elaboração de exercícios e questionários (BITTENCOURT, 1993). Dessa forma, o livro didático é um auxílio-base importante para os professores e, assim, torna-se imprescindível que o livro didático contenha textos que abordem os temas que precisam ser trabalhados em sala de aula tal como sexualidade.

\section{Sexualidade no Livro Didático}

Para Cassab e Martins (2003), o livro didático é um importante recurso para auxílio na prática pedagógica dos professores da educação básica. Partindo desse pressuposto, é importante ressaltar o que afirmam Souza e Coan (2013, p. 2) sobre os livros didáticos (LD) de Biologia: "O conteúdo de sexualidade nos livros didáticos nos tempos atuais não pode oferecer espaço para se alimentar tabus e mitos sexuais".

Gonçalves et al. (2013) realizaram a análise de 41 livros didáticos de diversas disciplinas, inclusive Biologia, acerca do tema sexualidade e verificaram que em $39 \%$ dos livros analisados o tema não era abordado em nenhum momento. Isso demonstra como o assunto ainda não é bem retratado na realidade escolar do estudante brasileiro. Esse trabalho mostra que mesmo com as discussões trazidas tanto por autores que fazem as correlações entre o contexto político, lutas feministas e movimentos sociais quanto pelos documentos oficiais da educação brasileira, os livros didáticos ainda abordam o tema sexualidade de forma pouco reflexiva, ou mesmo nem abordam.

Em estudo mais recente, Salton (2016) nos faz perceber que a abordagem da sexualidade humana por um viés estritamente biológico não se restringe apenas à prática docente no ambiente escolar, mas também está presente nos livros didáticos. $\mathrm{O}$ autor conclui dizendo que não é necessário negar os saberes biológicos no livro didático, mas a abordagem histórica e sociocultural para tratar de temas como gênero, por exemplo, é necessária.

Ao se tratar da questão de gênero, Martins e Hoffmann (2007) demonstraram que nos livros didáticos os papéis de gênero trazem de forma desigual o protagonismo do gênero masculino em detrimento do gênero feminino, assumindo que esse último possui um papel social secundário. As autoras concluem que na sociedade, considerando a diversidade social, sexual e de gênero, não há espaço para papéis fixos que traduzem um poder hegemônico de um grupo social, visto que a sociedade e a cultura, estão em constante mudança. Considerando essa última afirmação de Martins e Hoffmann (2007), em relação aos papéis sociais, os livros didáticos devem então se adequar a essas mudanças socioculturais. Assim, a linguagem sempre voltada ao que é considerado "normal" (heterossexual), ou voltada sempre ao gênero masculino remete à reafirmação da heteronormatividade da linguagem dos livros didáticos. Levando também ao controle de gênero e sexualidade, trazendo os dois conceitos correlacionados. De acordo com Anjos (2013, p. 14):

A heteronormatividade pode ser entendida como um conjunto de normas e regularização dos modos de ser e viver os desejos corporais e a sexualidade. A perspectiva da heteronormatividade gira em torno de discursos biologistas e deterministas, onde há unicamente uma forma binária de ser e viver, ou seja, 
feminino/fêmea ou masculino/macho, onde cada um só poderia interessar-se pelo sexo oposto.

Essa linguagem remete à ideia contrária do que seria o papel do livro didático dentro da sala de aula. Ao tratar do tema sexualidade, trazer menor diversidade e mais propensão a propagar ideias de anormalidade a tudo que foge do padrão heterossexual, pode dificultar a abordagem da diversidade, do respeito e da tolerância.

Em relação aos conteúdos da sexualidade humana, que tangem aspectos sociais, temos, por exemplo, a abordagem do planejamento familiar e gravidez na adolescência. Altmann (2001) enfatiza a importância da inclusão desses temas no livro didático, considerando a importância que o livro tem em guiar os conteúdos dentro da sala de aula.

\section{Programa Nacional do Livro e do Material Didático}

Os livros didáticos são disponibilizados às escolas públicas, no Brasil, pelo Programa Nacional do Livro e do Material Didático (PNLD). O Programa foi criado no ano de 1985, sendo considerado um passo importante para a educação brasileira no que diz respeito à distribuição sistemática e gratuita de LD, para a maior parte das escolas públicas de Ensino Fundamental do país. A partir de 2003, o Programa passou a distribuir também LD para o Ensino Médio e no ano de 2007, iniciou-se a distribuição dos livros de Biologia. Atualmente, as escolas públicas brasileiras recebem livros de todos os componentes curriculares da Educação Básica, através do PNLD (BRASIL, 2011).

Antes de chegarem às escolas, os livros são analisados por especialistas que elaboram uma lista de livros que comporão o guia dos livros didáticos. Esse guia é disponibilizado para as escolas da Educação Básica, que têm um período para realizarem a escolha da coleção que consideram mais conveniente para a escola. Os livros são substituídos a cada três anos, sendo esse o período em que ocorre um novo processo de escolha dos LD. A escolha das coleções era feita pelos professores da rede, para cada escola. No entanto, graças ao Art. 18 do Decreto n o 9099/2017 (BRASIL, 2017) essa deixou de ser exclusiva dos mesmos, podendo ser para cada escola, para cada grupo de escolas ou, ainda, para todas as escolas da rede, a depender da opção dos responsáveis pela rede. O guia apresenta as coleções didáticas aprovadas no processo de avaliação, disponibilizando aos professores da rede pública de ensino as características pedagógicas de cada uma delas. Além disso, encontra-se disponível no guia as fichas de avaliação que contêm os critérios utilizados na avaliação (BRASIL, 2014).

O Guia do PNLD de Biologia, de 2015, apresentou como um de seus critérios avaliativos, se a obra analisada:

\footnotetext{
Contribui para que os conhecimentos biológicos sirvam para reconhecer formas de discriminação racial, social, de gênero, bem como para a formação de atitudes, posturas e valores que eduquem os cidadãos no contexto étnico-racial para a construção de uma sociedade democrática (BRASIL, 2014, p. 12).
}

Sendo assim, segundo esse critério, para o livro ser aprovado, é importante que ele estimule a reflexão de temas sociais que dizem respeito à diversidade humana, seja ela social, 
de gênero ou racial. Como afirma Borrillo (2000), é na escola, por meio de instrumentos pedagógicos como o livro didático, que os estudantes entram em contato com conceitos e questões que formam o mundo como ele é e conseguem interpretá-lo, tendo como objetivo a valorização de princípios éticos como respeito à diversidade e a não discriminação, promovendo a tolerância e respeito.

Além do LD comum ao aluno e ao professor, o livro desse último possui um manual, o Manual do Professor, que contém diversas funções, dentre elas a de auxiliar o professor na utilização do LD, bem como no seu planejamento de aula. Esse manual também passa pela avaliação de especialistas, seguindo alguns critérios, é verificado se o manual:

\footnotetext{
Fornece possibilidades teórico-metodológicas que favoreçam o processo de ensinoaprendizagem, processos educativos emancipatórios (não excludentes) e $\mathrm{o}$ reconhecimento de formas de discriminação racial, social, de gênero, sexualidade e de como pode favorecer (BRASIL, 2014, p. 12).
}

Segundo o Guia do PNLD de 2015 Biologia, as obras aprovadas devem "superar a centralidade do viés biológico" (BRASIL, 2014, p. 24) e promover práticas que combatam a violência e o preconceito: "[...] enfrentamento das violências, preconceitos e discriminações de sexualidades, materializados em práticas sexistas, homofóbicas, transfóbicas, lesbofóbicas presentes, na atualidade, nos cotidianos das salas de aulas, da escola, da comunidade" (BRASIL, 2014, p. 24).

No ano de 2015 foram disponibilizados no Guia do PNLD Biologia nove diferentes coleções, para a escolha dos professores e posterior entrega nas escolas. Graças a essa distribuição gratuita do LD no território brasileiro, esse recurso se tornou bastante comum nas escolas, estando disponível para o acesso de alunos e professores. É possível perceber a importância do livro didático como recurso, não apenas para abordar a sexualidade humana, mas também para quebrar a "concepção biologicista" e conteudista em abordar temas relacionados à sexualidade humana restritos à Biologia e abrir espaço para conteúdos também voltados para as Ciências Humanas e Sociais.

Considerando a importância da escola e do livro didático na abordagem de temas sociais da sexualidade humana, como já apresentado, com o intuito de diminuir preconceitos e discriminações a fim de tornar a sociedade futura mais justa e igualitária no que concerne aos direitos entre os diferentes grupos sociais, como mulheres e membros da comunidade LGBT, entende-se a relevância desse estudo em mostrar como esse tema, sexualidade, é apresentado nos livros didáticos atuais, distribuídos pelo governo federal brasileiro, pelo Programa Nacional do Livro e do Material Didático no ano de 2015, além de verificar nas coleções dos mesmos autores no ano de 2018, se houve ou não alguma mudança substancial na forma de tratar o tema em questão.

\section{Metodologia}

Para a realização dessa pesquisa, foram selecionadas as duas coleções de livros didáticos de Biologia mais distribuídas no Brasil pelo PNLD, no ano de 2015 (Quadro 1), a 
partir de dados estatísticos fornecidos pelo Fundo Nacional de Desenvolvimento da Educação (FNDE) (www.fnde.gov.br). A escolha das duas coleções mais distribuídas pelo PNLD, no ano de 2015, deve-se ao fato de até o momento de início dessa pesquisa, ainda não terem sido divulgadas as coleções mais distribuídas pelo PNLD no ano de 2018. Segundo o site do FNDE, foram distribuídos, no ano de 2015, o total de 7.563.371 livros de Biologia, sendo $833.519(27,1 \%)$ da coleção 1 de 2015 e 537.155 (17,5\%) da coleção 2 de 2015 . Vale a pena ressaltar que apenas essas duas coleções correspondem 44,6\% da distribuição nacional. Além dessas, foram também analisadas as coleções dos mesmos autores, porém nas edições distribuídas pelo PNLD de 2018 (Quadro 1). Nesse ano, o total de exemplares de livros didáticos de Biologia distribuídos foi de 7.946.878, sendo 1.588.681 (20\%) da coleção 1 de 2018 e 1.975 .005 (24\%) referente à coleção 2 de 2018, 44\% do total distribuído. Como cada coleção possui 3 volumes, no total foram analisados doze livros.

Quadro 1. Coleções selecionadas para o estudo de acordo com a distribuição das mesmas no DF pelo PNLD 2015 e 2018.

\begin{tabular}{|l|c|}
\hline \multicolumn{1}{|c|}{ Coleções selecionadas } & Ano do PNLD \\
\hline $\begin{array}{l}\text { Coleção 1 - Biologia Hoje, Sérgio Linhares Fernando. 2a ed. - São Paulo: } \\
\text { Ática, 2013. }\end{array}$ & 2015 \\
\hline $\begin{array}{l}\text { Coleção 2 - Biologia em Contexto, Amabis, José Mariano e Martho, } \\
\text { Gilberto Rodrigues. 1 }{ }^{\text {a }} \text { ed. - São Paulo: Moderna, 2013. }\end{array}$ & 2015 \\
\hline $\begin{array}{l}\text { Coleção 1 - Biologia Hoje, Sérgio Linhares, Fernando Gewandsznajder, } \\
\text { Helena Pacca. 3a ed. - São Paulo: Ática, 2016. }\end{array}$ & 2018 \\
\hline $\begin{array}{l}\text { Coleção 2 - Biologia Moderna, Amabis, José Mariano e Martho, Gilberto } \\
\text { Rodrigues. 1 }{ }^{\text {a }} \text { ed. - São Paulo: Moderna, 2016. }\end{array}$ & 2018 \\
\hline
\end{tabular}

Fonte: Brasil (2014; 2017).

As coleções foram analisadas a partir da metodologia de análise de conteúdo proposta por Bardin (1977), utilizando o processo de categorização a posteriori, ou seja, construção de categorias após a análise do objeto de estudo. Para isso, os livros foram lidos e somente após essa leitura, as categorias foram determinadas. Bardin (1977) propõe técnicas que permitam a análise de conteúdo, sendo aqui utilizada a de categorização. A autora descreve o processo de categorização como "uma operação de classificação de elementos constitutivos de um conjunto por diferenciação e, em seguida, por reagrupamento segundo gênero (analogia), com os critérios previamente definidos" (BARDIN, 1977, p. 147).

Após a verificação dos conteúdos didáticos presentes nos livros e leitura dos capítulos que traziam questões relacionadas à sexualidade, foram criadas duas categorias para análise de textos das coleções: "Concepção Biologicista" e "Aspectos Sociais". Para a categoria "Concepção Biologicista" foram considerados os seguintes conteúdos: ciclo menstrual, reprodução, métodos contraceptivos e infecções sexualmente transmissíveis. Já para a categoria "Aspectos Sociais", os conteúdos considerados foram: orientação sexual, identidade de gênero, aborto e planejamento familiar. 
Segundo Furlani (2011) essa abordagem centrada na reprodução, na caracterização de gêneros de acordo com atributos corporais e nas infecções sexualmente transmissíveis se caracteriza pelo determinismo biológico, por meio de uma linguagem mais técnica e conteudista. Esse fato justifica a criação da categoria "Concepção Biologicista”, após a leitura das coleções, e a inclusão desses conteúdos nela.

Para a categoria "Aspectos Sociais" foram considerados os conteúdos de orientação sexual, identidade de gênero, aborto e planejamento familiar. Os conteúdos inseridos nessa categoria - orientação sexual, identidade de gênero, aborto e planejamento familiar geralmente estão relacionados às formas de preconceito e, portanto, relacionados aos sujeitos sociais, diferentemente dos temas categorizados como "biologicistas", o que justifica a criação dessa categoria após a leitura das coleções e a inserção desses conteúdos nela.

Em cada uma dessas categorias foram analisadas: i) A clareza na linguagem: em que foi averiguada se a linguagem utilizada nos textos era clara, de fácil entendimento pelos alunos e se induziam à reflexão e ao pensamento crítico do aluno; e, ii) Os equívocos: onde foi verificada a existência de erros conceituais dentro dos conteúdos encontrados.

Após a categorização, os dados foram organizados quantificando o número de vezes que os conteúdos de cada categoria eram tratados nos diferentes textos, com a finalidade de evidenciar mais objetivamente os resultados encontrados após a análise. Além de quantificar, foram descritas as impressões obtidas sobre a maneira como cada conteúdo foi abordado. Foi, também, analisado o Manual do Professor, que se encontra ao final de cada livro didático, a fim de verificar como são feitas as orientações ao docente sobre a abordagem do tema sexualidade. Para essa análise, foram realizadas descrições de como essas orientações estão apresentadas.

\section{Resultados e discussão}

\section{Coleção 1 Biologia Hoje (2015 e 2018)}

A partir dos resultados obtidos e como pode ser observado na tabela 1, verifica-se que os conteúdos da categoria "Concepção Biologicista" foram mais frequentes do que aqueles da categoria "Aspectos Sociais". Os conteúdos dessa última categoria são mencionados uma ou nenhuma vez, salvo na edição do PNLD de 2018, em que o conteúdo Orientação Sexual foi mencionado duas vezes. 
Tabela 1. Frequência dos conteúdos analisados nas categorias Concepção Biologicista e Aspectos Sociais, nas coleções Biologia Hoje PNLD 2015 e PNLD 2018.

\begin{tabular}{lll}
\hline Concepção Biologicista & PNLD 2015 & PNLD 2018 \\
\hline Ciclo Menstrual & 3 vezes & 3 vezes \\
Reprodução & 4 vezes & 5 vezes \\
Métodos Contraceptivos & 3 vezes & 3 vezes \\
IST`s & 2 vezes & 2 vezes \\
\hline Aspectos Sociais & PNLD 2015 & PNLD 2018 \\
\hline Orientação Sexual & 1 vez & 2 vezes \\
Identidade de Gênero & Nenhuma vez & Nenhuma vez \\
Aborto & 1 vez & 1 vez \\
Planejamento Familiar & 1 vez & 1 vez \\
\hline
\end{tabular}

Fonte: Elaborado pelos autores.

De modo geral, os conteúdos analisados na categoria "Concepção Biologicista" seguiram um padrão de abordagem mais técnica, se restringindo à fisiologia, falando de reprodução, ciclo menstrual, IST`s e métodos contraceptivos de uma forma mais conteudista. Entretanto, na edição do PNDL 2018, há um contraponto no texto sobre reprodução, não vinculando necessariamente a reprodução ao ato sexual, mas relacionando este fato às relações não heterossexuais e aos casais heterossexuais que utilizam métodos contraceptivos, como mostra o seguinte trecho:

\footnotetext{
O ato sexual, no entanto, não envolve necessariamente a reprodução. Isso se explica pelo fato de o sexo abranger também relações diferentes daquela que envolve uma mulher e um homem [...] e existem relações entre pessoas de sexos diferentes que utilizam algum método para evitar a reprodução, os métodos contraceptivos (LINHARES; GEWANDSZNAJDER; PACCA, 2016, p. 164).
}

Apesar do contraponto mencionado acima, no que tange a categoria "Aspectos Sociais" no conteúdo orientação sexual, em nenhuma das coleções se verificou um aprofundamento no tema e nem a apresentação de novas informações, restringindo-se em apenas conceituar a questão heterossexual-homossexual, não mencionando outras variações da sexualidade humana, como a bissexualidade.

A temática identidade de gênero não chegou a ser abordada em nenhuma das duas edições da Coleção 1. A falta dessa abordagem fica em desacordo com o proposto pelo PNLD, já que segundo o Guia do PNLD 2015 Biologia (BRASIL, 2014), o livro didático, para ser aprovado, deve fornecer meios para o combate às práticas sexistas e transfóbicas. Entretanto, a falta de abordagem do assunto, nos textos dos livros analisados, não abre espaço para o debate necessário e recomendado pelo PNLD.

Em relação ao conteúdo aborto, as coleções trazem o mesmo texto informativo nas edições distribuídas nos anos de 2015 e 2018, evidenciando opiniões divergentes a respeito 
do tema, de maneira expositiva, mas sem estimular nenhuma reflexão ao aluno. $\mathrm{O}$ aborto representa um problema de saúde pública no Brasil e segundo Temp et al. (2013, p. 73):

\begin{abstract}
O sistema educacional brasileiro representa um meio de formação de cidadãos capaz de construir conhecimentos que contribuam para a redução do número de abortos e suas complicações, principalmente entre adolescentes. Considerando-se este aspecto, as ações de educação em saúde, desenvolvidas no campo da sexualidade junto a este público, são fundamentais e contribuem para um estilo de vida mais saudável e tomada de decisões mais conscientes.
\end{abstract}

Nesse sentido, consideramos que o trecho apresentado cumpre seu papel em evidenciar as divergências de opiniões sobre o conteúdo. No entanto, ao evidenciar essas opiniões, as coleções as apresentam de maneira expositiva, sem estimular nenhuma reflexão ao aluno, não despertando no estudante o pensar como um sujeito social sobre o tema e seus desdobramentos, como, por exemplo, a discussão de sua legalização.

O tema planejamento familiar não foi abordado em nenhum texto, em nenhuma das duas edições, das coleções distribuídas. No entanto, em ambas as coleções, foi considerado o trecho do texto que trata sobre procedimentos de esterilização, quando os autores afirmam a importância do direito de escolha e o preparo, do homem e da mulher, sobre quando devem ter um filho. $\mathrm{O}$ viés em abordar esses temas se limita a falar de Métodos Contraceptivos, ou seja, se limita ao viés biológico, sem falar quase nada das questões sociais que acompanham o planejamento familiar. Como mostram os trabalhos de Altmann (2001), a negligência em abordar o planejamento familiar, nas escolas e nos livros didáticos, pode gerar gravidez indesejada e gravidez na adolescência, sendo que esta última tem grande impacto no abandono escolar por parte das alunas grávidas.

O manual do professor orienta bem sobre conteúdos considerados na categoria "Concepção Biologicista", trazendo artigos e referências que possam ajudar o professor na abordagem dos temas. Para os conteúdos classificados na categoria "Aspectos Sociais", o manual estimula que tais conteúdos sejam debatidos, mas não traz orientações ou sugestões de como abordar os temas. O que nos mostra a continuidade em abordar temas "biologicistas" em detrimento de temas que são transversais às Ciências Sociais.

As informações e os conteúdos dispostos nos livros que compõem as edições da Coleção 1, em ambas as categorias analisadas, fizeram uso de uma linguagem de fácil entendimento, sem fazer utilização de palavras extremamente rebuscadas ou construindo textos prolixos. Em relação à disposição, construção e aprofundamento dos textos didáticos, foi observado que os conteúdos da categoria "Concepção Biologicista" estavam dispostos em textos descritivos dentro do capítulo, além disso os textos eram extensos e aprofundavam o conteúdo, utilizando terminologias da área de Ciências Biológicas. Já para os conteúdos da categoria "Aspectos Sociais", os textos eram bem menores, estritamente descritivos e sem aprofundamento no conteúdo. Além disso, todos os conteúdos que estão enquadrados na categoria "Aspectos Sociais", em ambas as Coleções distribuídas pelo PNLD, sempre estavam dispostos em um quadro intitulado "Biologia e Sociedade", sem relacionar esses conteúdos com o apresentado no restante do capítulo. 


\section{Coleção 2 Biologia em Contexto (2015) e Biologia Moderna (2018)}

Embora as duas coleções distribuídas pelo PNLD 2015 e 2018 possuam nomes diferentes, elas foram escritas pelos mesmos autores, por isso foram analisadas. Assim como na coleção anteriormente apresentada, a frequência de conteúdos na categoria "Concepção Biologicista" foi maior do que aqueles dispostos na categoria "Aspectos Sociais", como pode ser verificado na tabela 2 .

Tabela 2. Frequência dos conteúdos analisados nas categorias Concepção Biologicista e Aspectos Sociais, nas coleções Biologia em Contexto PNLD 2015 e Biologia Moderna PNLD 2018.

\begin{tabular}{lll}
\hline Concepção Biologicista & PNLD 2015 & PNLD 2018 \\
\hline Ciclo Menstrual & 3 vezes & 3 vezes \\
Reprodução & 9 vezes & 5 vezes \\
Métodos Contraceptivos & 2 vezes & 2 vezes \\
IST`s & 1 vez & 1 vez \\
\hline Aspectos Sociais & PNLD 2015 & PNLD 2018 \\
\hline Orientação Sexual & Nenhuma vez & 1 vez \\
Identidade de Gênero & Nenhuma vez & 1 vez \\
Aborto & 2 vezes & 1 vez \\
Planejamento Familiar & 1 vez & 1 vez \\
\hline
\end{tabular}

Fonte: Elaborado pelos autores.

No entanto, alguns pontos interessantes foram percebidos ao longo da análise dessas coleções. O primeiro deles trata do teor dos conteúdos da "Concepção Biologicista", que foram voltados unicamente para a reprodução em seu significado fisiológico, com o intuito sempre de geração de novos indivíduos e perpetuação de genes.

Outro ponto que merece destaque é a temática ciclo menstrual. Essa, por exemplo, tem o parto como o ponto guia do ciclo menstrual e hormonal passando a percepção de que a maternidade é a finalidade da mulher. Essa é reforçada quando se trata do assunto reprodução, em que constantemente é utilizada erroneamente como sinônimo de sexualidade.

A ideia biológica de que a reprodução é um dos pilares que movimenta a vida e a evolução é bastante difundida, percepção que Rohden (2002) e Anjos (2013) também discutiram. Porém, aplicar esse conceito para o ser humano, especialmente dentro da escola, pode ser um fator que gere discriminações e traga uma ideia de que o papel da mulher na sociedade é apenas a geração de descendentes. Esse papel de progenitora também é reforçado na linguagem utilizada pelo livro, especialmente ao descrever o órgão sexual de homens e mulheres, utilizando a palavra orgasmo apenas para a descrição masculina, enquanto a 
descrição feminina se mantém no viés reprodutivo do parto, como se o prazer não pertencesse ao feminino.

O tema ISTs destaca-se nessa coleção por não ser abordado de maneira mais profunda, uma vez que a sua aparição se restringe a um trecho em um texto sobre métodos contraceptivos. O destaque é feito pela falta de abordagem sobre esse tema, o que traz certa preocupação, pois uma forma de evitar o aumento do contágio de ISTs é tratar o tema dentro de salas de aulas. Essa abordagem tem o intuito de conscientizar os alunos, especialmente na adolescência em que a sexualidade é aflorada, uma vez que a estratégia básica de prevenção de ISTs se dá por meio de medidas educativas (MALTA; MARTINS; ALMEIDA, 2013). Essa falta de abordagem sobre as ISTs dentro dos livros didáticos também foi percebida por Anjos (2013), em seu trabalho.

Já tratando do tema anticoncepcionais, ainda na categoria "Concepção Biologicista", os livros trazem um texto sobre contraceptivos masculinos, abordando então o balanceamento de responsabilidade, uma vez que a grande maioria dos métodos contraceptivos são voltados para as mulheres. Essa abordagem mais voltada para as mulheres, apresenta uma visão novamente de desigualdade de gênero, pois a "responsabilidade" é jogada para um gênero apenas, o feminino.

A força e a dominação são características atribuídas ao gênero masculino e as características hormonais são explicadas para o gênero, mas quando se trata da construção do gênero feminino, existe apenas a associação aos hormônios da gravidez, vinculando o destino biológico da gravidez à esse gênero (ANJOS, 2013). Essa diferença, ainda que sutil, nos textos, reforça o papel materno e reprodutivo da mulher e desvincula o homem dessa responsabilidade.

Ao analisar os conteúdos da categoria "Aspectos Sociais" existe uma diferença, ainda que pequena, entre as coleções que compõem os livros distribuídos pelo PNLD de 2015 e de 2018, especialmente referente aos temas orientação sexual e identidade de gênero, que não foram abordados de forma alguma na coleção de 2015, mas que aparecem na coleção de 2018 (Tabela 2). Entretanto, o tema ainda é tratado de forma mais simplista quando comparado aos conteúdos da "Concepção Biologicista", podendo passar a impressão, ao leitor, de que o tema não requer tamanha profundidade e riqueza de detalhes. Os temas classificados dentro da categoria "Concepção Biologicista", são, ainda, discutidos e trabalhados em textos mais extensos quando comparados aos textos enquadrados na categoria "Aspectos Sociais", que mesmo presentes dentro dos livros didáticos, possuem pouca carga de conteúdo, o que pode dificultar o embasamento para discussões e abordagens dentro das salas de aula.

A linguagem utilizada nos textos biológicos contribui para uma heteronormatividade da sexualidade. A abundância de exemplos e as formas vinculadas à heterossexualidade evocam, muitas vezes, a noção de família restrita ao sentido tradicional: pai, mãe e filhos (GONÇALVES; PINTO; BORGES, 2013). Essa heteronormatização pode acabar contribuindo para a homofobia, dando a ideia de que tudo que foge do "padrão heterossexual" é anormal. A linguagem utilizada é simples e não propõe a reflexão, dentro do próprio texto, sobre todos os aspectos e contextos que a sexualidade pode trazer dentro da sociedade, encarregando o professor de tal tarefa. No entanto, o manual do professor, 
analisado na coleção, não traz orientações explícitas de abordagem do tema ou direcionamentos de como instigar a discussão. Essa falta de informação no manual acaba por deixar a cargo do professor, por si só, o aprofundamento na abordagem dessas questões que, muitas vezes, são deixadas de lado, devido ao fato de que o docente nem sempre é preparado na vida acadêmica para falar sobre sexualidade, levando consigo tabus e preconceitos que podem ser perpetuados na escola.

A linguagem dos textos, em ambas as categorias, apresentou ser de fácil entendimento para o leitor, mesmo apresentando diversos nomes diferentes, o texto possui uma fluidez que auxilia a leitura sem dificuldades, apesar de, muitas vezes, a linguagem ser extremamente simplista, especialmente em textos da categoria "Aspectos Sociais". Poucos erros conceituais foram encontrados nos textos analisados. Os equívocos que mais chamaram a atenção foram: o livro tratar a testosterona como hormônio exclusivamente masculino (sendo ele determinista para a definição do sexo na fase embrionária do desenvolvimento humano), o que é sabido não ser exatamente assim. Outro ponto de equívoco foi percebido ao tratar o DIU como método abortivo além de contraceptivo, o que é um conceito de fato errado, pois o DIU não possui efeitos abortivos, mas anticonceptivos atuando como barreira afim de evitar a fecundação.

Por fim, verificou-se que em ambas as coleções analisadas, os textos referentes aos temas da categoria "Aspectos Sociais", embora presentes, foram apresentados de forma superficial. Ambas as coleções explicam o significado de cada conteúdo, sem se aprofundar no tema, não deixando explícito que existem outros espectros da sexualidade humana e como as relações afetivas são mais profundas do que apenas a descrição objetiva que os livros propõem.

\section{Considerações finais}

Os livros didáticos possuem um papel essencial na formação educacional dos alunos, por conterem as informações dos conteúdos e para o professor, atuando como um guia para a abordagem de conteúdos dentro da sala de aula. Ao trazer reflexões e discussões de cunho social nos livros didáticos, tiramos da mão exclusiva do professor a decisão de trabalhar ou não, de discutir ou não, uma vez que o aluno tem acesso a esse livro, que é distribuído para a maioria dos alunos da Educação Básica pública do país.

Ao se pensar nos livros didáticos como um norteador para a prática pedagógica, neles deveriam estar contidas sugestões de como abordar a temática sexualidade dentro da sala de aula, auxiliando o professor nessa tarefa. As coleções analisadas apresentam mudanças sutis entre as edições distribuídas nos PNLD de 2015 e 2018. Sendo possível verificar que o tema sexualidade foi pouco abordado dentro dos capítulos dos livros analisados, mostrando ser um assunto ainda escasso, como apresentado anteriormente, sendo necessária a incorporação da visão social no material disponibilizado para as escolas.

Um ponto de preocupação surge ao se verificar a Base Nacional Comum Curricular (BNCC) do Ensino Médio, homologada no ano de 2018. Ao se realizar uma busca rápida 
pelo termo sexualidade nesse documento, pode-se constatar que o mesmo não é abordado em nenhum momento no "Novo Ensino Médio". Sendo assim, vale a pena verificar se no ano de 2021, quando os livros didáticos de Biologia do Ensino Médio já estiverem adequados ao currículo que tem por base a BNCC, como o tema sexualidade será tratado. Pode ser que o mesmo seja, ainda, menos abordado dentro dos livros didáticos de Biologia, já que a BNCC não faz nenhuma menção ao tema nesse segmento. Esse fato pode levar a uma diminuição mais drástica das possibilidades de discussão de temas tão relevantes dentro da sala de aula, afastando o critério de construção de uma sociedade democrática, sugerida na legislação brasileira.

\section{Referências}

ALTMANN, Helena. Orientação sexual nos parâmetros curriculares nacionais. Revista Estudos Feministas, Florianópolis, v. 9, n. 2, p. 575-585, 2001.

https://doi.org/10.1590/S0104-026X2001000200014

AMABIS, José Mariano; MARTHO, Gilberto Rodrigues. Biologia em Contexto. 1. ed. São Paulo: Moderna, 2013.

AMABIS, José Mariano; MARTHO, Gilberto Rodrigues. Biologia Moderna. 1. ed. São Paulo: Moderna, 2016.

ANJOS, Roberta Oliveira dos. Construção de gênero e de sexualidade no livro didático de Biologia. 2013. 43 f. Monografia (Graduação do Curso de Ciências Biológicas) - Instituto de Biociências, Universidade Federal do Rio Grande do Sul, Porto Alegre, 2013.

BARDIN, Laurence. Análise de Conteúdo. 1. ed. São Paulo: Edições 70, 1977.

BERALDO, Flávia Nunes de Moraes. Sexualidade e escola: espaço de intervenção.

Psicologia Escolar e Educacional, Campinas, v. 7, n. 1, p. 103-104, jun. 2003. https://doi.org/10.1590/S1413-85572003000100012

BITTENCOURT, Circe Maria Fernandes. Livro didático e conhecimento histórico: uma história do saber escolar. 1993. 383 f. Tese (Doutorado em História Social) - Faculdade de Filosofia, Letras e Ciências Humanas, Universidade de São Paulo, São Paulo, 1993. https://doi.org/10.11606/T.8.2019.tde-28062019-175122

BORRILLO, Daniel. L’homophobie. Paris: Presses Universitaires de France, 2000.

BRASIL. Guia de Livros didáticos: PNLD 2012. Brasília: MEC, SEB, 2011.

BRASIL. Guia de Livros Didáticos: PNLD 2015: Biologia: Ensino Médio. Brasília: MEC, SEB, 2014.

BRASIL. Guia de Livros Didáticos: PNLD 2018: Biologia: Ensino Médio. Brasília: MEC, SEB, 2017. 
BUTLER, Judith. Regulações de gênero. Cadernos Pagu, Campinas, n. 42, p. 249-274, 2016.

CANO, Maria Aparecida Tedeschi; FERRIANI, Maria das Graças Carvalho; GOMES, Romeu. Sexualidade na adolescência: um estudo bibliográfico. Revista Latino-Americana de Enfermagem, Ribeirão Preto, v. 8, n. 2, p. 18-24, abr. 2000.

https://doi.org/10.1590/S0104-11692000000200004

CASSAB, Mariana; MARTINS, Isabel. A escolha do livro didático em questão. In: ENCONTRO NACIONAL DE PESQUISA EM EDUCAÇÃO EM CIÊNCIAS, 4., Bauru, 2003. Anais... Bauru: ABRAPEC, 2003.

DINIZ, Debora; PEREIRA, Lucélia Luiz. Educação sexual para adolescentes: um estudo sobre as moralidades dos aconselhadores. SER Social, Brasília, n. 10, p. 225-240, 2009. https://doi.org/10.26512/ser_social.v0i10.12921

FURLANI, Jimena. Educação sexual na sala de aula: relações de gênero, orientação sexual e igualdade étnico-racial numa proposta de respeito às diferenças. Belo Horizonte: Autêntica, 2011.

GONÇALVES, Eliane; PINTO, Joana Plaza; BORGES, Lenise Santana. Imagens que falam, silêncios que organizam: sexualidade e marcas de homofobia em livros didáticos brasileiros. Currículo sem Fronteiras, v. 13, n. 2, p. 35-61, jan./abr. 2013.

IMPERATORI, Thaís et al. Qual diversidade sexual dos livros didáticos brasileiros? In: SEMINÁRIO INTERNACIONAL FAZENDO GÊNERO: Corpo, Violência e Poder, 8., Florianópolis, 2008. Anais... Florianópolis: UFSC, 2008.

LINHARES, Sérgio; GEWANDSZNAJDER, Fernando. Biologia Hoje. 2. ed. São Paulo: Ática, 2013.

LINHARES, Sérgio; GEWANDSZNAJDER, Fernando; PACCA, Helena. Biologia Hoje. 3. ed. São Paulo: Ática, 2016.

LOURO, Guacira Lopes (org.). O corpo educado: pedagogias da sexualidade. 2. ed. Belo Horizonte: Autêntica, 2000.

MACEDO, Senei da Rocha Henrique et al. Adolescência e sexualidade: scripts sexuais a partir das representações sociais. Revista Brasileira de Enfermagem, Brasília, v. 66, n. 1, p. 103-109, 2013. https://doi.org/10.1590/S0034-71672013000100016

MAIA, Ana Cláudia Bortolozzi. Conceito amplo de sexualidade no processo de educação sexual. Psicopedagogia On Line, v. 1, 2010.

MALTA, Elma de Carvalho; MARTINS, Magaiva Rocha; ALMEIDA, Maria de Fátima. Avaliação do conhecimento dos adolescentes sobre infecções sexualmente transmissíveis.

Revista de Enfermagem UFPE On Line, Recife, v. 7, n. especial, p. 7042-7047, dez. 2013. 
MARTINS, Eliecília de Fátima; HOFFMANN, Zara. Os papéis de gênero nos livros didáticos de Ciências. Revista Ensaio, Belo Horizonte, v. 9, n. 1, p. 132-151, jan./jun. 2007. https://doi.org/10.1590/1983-21172007090109

RIBEIRO, Marçal; RENNES, Paulo. Educação sexual além da informação. São Paulo: EPU, 1990.

ROHDEN, Fabíola. Ginecologia, gênero e sexualidade na ciência do século XIX. Horizontes Antropológicos, Porto Alegre, ano 8, n. 17, p. 101-125, jun. 2002.

https://doi.org/10.1590/S0104-71832002000100006

SALTON, Aguinaldo. Livros didáticos de Biologia: corpo, gênero e sexualidade. 2016. 13 f. Monografia (Especialização em Gênero e Diversidade na Escola) - Universidade Federal do Paraná, Curitiba, 2016.

SILVA, Ariana Kelly Leandra Silva da. Diversidade sexual e de gênero: a construção do sujeito social. Revista do NUFEN, São Paulo, v. 5, n. 1, p. 12-25, 2013.

SOUZA, Solange Lemes de; COAN, Cherlei Marcia. Abordagem da sexualidade humana em livros didáticos de Biologia. In: SIMPÓSIO INTERNACIONAL DE EDUCAÇÃO SEXUAL, 3., Maringá, 2013. Anais... Maringá: UEM, 2013.

TEIXEIRA, Camila Sabino; ARAÚJO, Cleide Sandra Tavares; SOUZA, Edna Duarte de. Sexualidade e Educação Sexual: a produção científica brasileira e a conceituação básica adotada. In: CONGRESSO DE ENSINO, PESQUISA E EXTENSÃO DA UEG, 4. , Anápolis, 2017. Anais... Anápolis: UEG, 2017.

TEMP, Daiana Sonego et al. Desenvolvimento do Tema Aborto em Escola Pública: uma experiência através de atividades lúdicas. Revista Ensino de Ciências, Rio de Janeiro, v. 4, n. 1, p. 68-88, jan. 2013. http://dx.doi.org/10.18250/2179-2933/ensinodeciencias.v4n1p68-88

Checagem Antiplágio

Crossref Similarity Check
Distribuído sobre

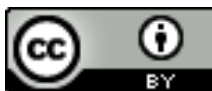

